
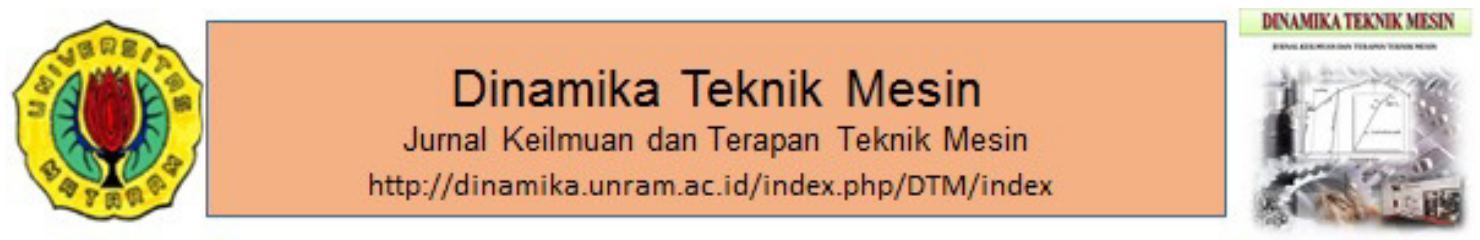

\title{
Variasi sudut pemasangan tabung kompresor terhadap unjuk kerja pompa hidram
}

\author{
R. Sutanto ${ }^{1 *}$, K. Wardani ${ }^{2}$, I.B. Alit ${ }^{1}$, M. Wirawan ${ }^{1}$ \\ ${ }^{1}$ Teknik Mesin Fakultas Teknik Universitas Mataram, Jln. Majapahit No. 62 Mataram Nusa Tenggara \\ Barat Kode Pos : 83125, Telp. (0370) 636087; 636126; ext 128 Fax (0370) 636087. \\ ${ }^{2}$ Balai Wilayah Sungai Nusa Tenggara I \\ *Email: r_sutanto10@yahoo.com
}

\begin{tabular}{l}
\hline ARTICLE INFO \\
\hline Article History: \\
Received 25 February 2018 \\
Accepted 14 April 2018 \\
Available online 1 July 2018 \\
\hline
\end{tabular}

Keywords:

Hydrant pump,

Variation,

Pressure,

Volumetric rate,

Efficiency.

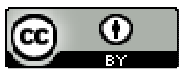

\begin{abstract}
Water is one of the factors which very important and necessary in the life of living creatures. Therefore, water must be available whenever and wherever in the quantity, timing, and sufficient quality. Hydraulic ram pump is a pump which does not require external energy as the power source. The purpose of this research is to understand the influence of the mounting tube compressor with tilt angle from the water weight-lift of output pipe. This research uses hydrant pump with a dimension of the compressor of 3 inches (in diameter) and $60 \mathrm{~cm}$ (in height). The falling angle of the pump is $35^{\circ}$. The falling-height is 2 meter with 4 variations of weight-lift $4,4 \frac{1}{2}$, and 5 meters. The method of analysis is conducted by analyzing data obtained in the experiment, while the results are presented in the form of tables and graphs. The results of the research shows that the best volumetric rate output is about $0.035 \mathrm{l} / \mathrm{s}$ at the mounting tube compressor of $90^{\circ}$ and 4 meters water weight-lift, while the lowest volumetric rate output is $0.011 \mathrm{l} / \mathrm{s}$ at the 5 meters water weight-lift. The best efficiency is $27.3 \%$ at the mounting tube compressor of $90^{\circ}$ with 4 meters of water weight-lift, while the lowest efficiency is $6.5 \%$ at the mounting tube compressor of $90^{\circ}$ and the 5 meters of water weight-lift.
\end{abstract}

\section{PENDAHULUAN}

Pompa merupakan salah satu jenis alat yang berfungsi untuk memindahkan zat cair dari suatu tempat ke tempat yang diinginkan. Zat cair tersebut contohnya adalah air, oli serta fluida lainnya yang tak mampu mampat. Pompa hidram atau singkatan dari hydraulic ram berasal dari kata hydro (air) dan ram (hantaman / pukulan) sehingga dapat diartikan menjadi tekanan air. Berdasarkan definisi tersebut maka pompa hidram dapat diartikan sebagai sebuah pompa yang energi atau tenaga penggeraknya berasal dari tekanan atau hantaman air yang masuk ke dalam pompa melalui pipa.Untuk itu, masuknya air yang berasal dari sumber air ke dalam pompa harus berjalan secara kontinyu atau terus menerus agar pompa dapat terus bekerja.

Penentuan kecepatan di sejumlah titik pada suatu penampang memungkinkan untuk membantu dalam menentukan besarnya kapasitas aliran sehingga pengukuran kecepatan merupakan fase yang sangat penting dalam 
menganalisa suatu aliran fluida. Kecepatan dapat diperoleh dengan melakukan pengukuran terhadap waktu yang dibutuhkan suatu partikel yang dikenali untuk bergerak sepanjang jarak yang telah ditentukan.

Besarnya kecepatan aliran fluida pada suatu pipa mendekati nol pada dinding pipa dan mencapai maksimum pada tengahtengah pipa. Kecepatan biasanya sudah cukup untuk menempatkan kekeliruan yang tidak serius dalam masalah aliran fluida sehingga penggunaan kecepatan sesungguhnya adalah pada penampang aliran. Bentuk kecepatan yang digunakan pada aliran fluida umumnya menunjukkan kecepatan yang sebenarnya jika tidak ada keterangan lain yang disebutkan.

Metode yang digunakan dalam menentukan efisiensi dari intalasi pompa hidram yaitu metode D' Aubission dengan persamaan:

$\eta=\frac{\mathrm{Q} 1 \times \mathrm{b} 1}{\mathrm{Q} 2 \times \mathrm{h} 2} \times 100 \%$

Dimana:

$\eta \quad$ : Efisiensi pompa hidram

Q1 : Debit air output (I/dtk)

Q2 : Debit air input (l/dtk)

h1 : Tinggi air angkat atau output (m)

$h 2$ : Tinggi terjunan air atau input $(\mathrm{m})$ Juliadi (2011) melakukan penelitian tentang analisa variasi jumlah katup limbah dan susunan pompa terhadap unjuk kerja pompa hidram (hydraulic ram). Dari hasil penelitian tersebut didapatkan debit output terbesar pada ketinggian pemompaan maksimum (head maximum) diperoleh pada variasi susunan pompa IKL dan satu katup limbah yaitu sebesar $0,0419 \mathrm{l} / \mathrm{s}$. Hasil lain dari penelitian ini menunjukan variasi susunan IKL menghasilkan efisiensin yang lebih besar dari pada variasi susunan ILK yaitu $43,7 \%$ dengan satu katup limbah dan $47 \%$ dengan dua katup limbah.

Penelitian lainnya yang juga pernah dilakukan yaitu untuk mengetahui unjuk kerja pompa hidram dengan variasi tinggi serta posisi tabung kompresor. Tabung kompresor yang digunakan yaitu dengan diameter 3 inchi dengan tinggi tabung $25 \mathrm{~cm}, 40 \mathrm{~cm}, 50 \mathrm{~cm}$, dan $60 \mathrm{~cm}$. Hasil penelitian menunjukan bahwa head pemompaan tertinggi didapat pada saat penggunaan tinggi tabung kompresor $25 \mathrm{~cm}$ yaitu $34 \mathrm{~m}$ dengan posisi pemasangan ILK sedangkan efisiensi terbesar hingga 44,4 \% pada penggunaan tinggi tabung $60 \mathrm{~cm}$ dengan posisi ILK dan kapasitas pemompaan terbesar mencapai $0,0043 \mathrm{l} / \mathrm{s}$ pada posisi ILK dan tinggi tabung $60 \mathrm{~cm}$ (Jaelani, 2011).
Putra (2010) meneliti tentang pengaruh variasi tinggi terjunan dan sudut terjunan terhadap head pemompaan. Variabel bebasnya terdiri atas tinggi terjunan dan sudut terjunan. Variabel terikatnya adalah tekanan suction, tekanan tabung kompresi, tekanan discharge, debit suction dan debit discharge. Hasil penelitian menunjukan ada pengaruh variasi tinggi terjunan dan sudut terjunan terhadap head pemompaan dan efisiensi pada pompa hidram. Pada variasi tinggi terjunan, head pemompaan tertinggi terjadi pada tinggi $4 \mathrm{~m}$. Sedangkan pada variasi sudut terjunan head pemompaan terbesar terjadi pada sudut terjunan $45^{\circ}$.

Penelitian lainnya telah dilakukan terkait dengan pompa hidram oleh Suparman Ahmadi, dkk (2014) yaitu meneliti pengaruh variasi debit input dan variasi tinggi keluaran tabung kompresor (Air Chamber) terhadap efisiensi yang dihasilkan. Pada penelitian ini digunakan pompa hidram dengan spesifikasi tabung kompresor (Air Cahamber) 3 inchi dengan tinggi $60 \mathrm{~cm}$. Pada tabung kompresor pompa hidram dibuat lima variasi tinggi keluaran dengan jarak masing masing keluaran $10 \mathrm{~cm}$ dari badan pompa. Tinggi level air yang digunakan 6 meter dari pompa dan tinggi angkat air atau output digunakan 9,2 meter. Sedangkan parameter yang diukur adalah debit input, debit output, dan efisiensi. Dari penelitian diperoleh bahwa variasi tinggi keluaran yang menghasilkan debit output yang paling besar adalah pada tinggi keluaran $10 \mathrm{~cm}$ yaitu $102,24 \mathrm{ml} / \mathrm{s}$ untuk variasi debit input 12,42 l/s, sedangkan debit output yang paling rendah dihasilkan oleh tinggi keluaran $50 \mathrm{~cm}$ yaitu 42,08 $\mathrm{ml} / \mathrm{s}$ untuk variasi debit input $1,73 \mathrm{l} / \mathrm{s}$. Sedangkan efisiensi yang paling tinggi yaitu 5,084\% diperoleh dari tinggi keluaran $10 \mathrm{~cm}$ dengan debit input $1,73 \mathrm{l} / \mathrm{s}$ dan efisiensi yang paling rendah yaitu $1,023 \%$ diperoleh dari tinggi keluaran $50 \mathrm{~cm}$ dengan debit input 12,42 l/s.

Susana dan Sutanto (2016) melakukan pengujian terhadap tabung kompresor yang diletakkan setelah input dan katup limbah dengan saluran keluar berada dibawah tabung kompresor, memberikan pengaruh yang signifikan terhadap unjuk kerja pompa hudram. Berdasarkan hasil pengujian didapatkan bahwa debit output terbesar terjadi pada tinggi terjunan 4,1 $\mathrm{m}$ dan meningkat dari $0,112 \mathrm{l} / \mathrm{s}$ pada susunan IKL menjadi $0,121 \mathrm{l} / \mathrm{s}$ atau $121 \mathrm{ml} / \mathrm{s}$ yang tersusun ILK. Head maksimum terbesar terjadi pada tinggi terjunan 4,1 $\mathrm{m}$ dan meningkat dari 12 $\mathrm{m}$ pada susunan IKL menjadi $16 \mathrm{~m}$ pada susunan ILK.

\section{METODE PENELITIAN}

Penelitian ini dilakukan dengan menggunakan metode eksperimen yaitu dengan 
melakukan pengujian di lapangan agar didapatkan data-data yang diinginkan.

Variabel-variabel penelitian,

a. Variabel terikat, merupakan variabel yang menjadi perhatian utama dari penelitian. Variabel terikat pada penelitian ini adalah tekanan output, tekanan maksimum, tekanan tabung kompresor, debit air limbah, debit output dan efisiensi. b. Variabel bebas, merupakan yang mempengaruhi variabel terikat. Adapun yang menjadikan variabel bebas pada penelitian ini adalah variasi pemasangan tabung kompresor dengan sudut $0^{\circ}, 45^{\circ}$, dan $90^{\circ}$ dengan tinggi keluaran $4 \mathrm{~m}, 4.5 \mathrm{~m}$ dan $5 \mathrm{~m}$.

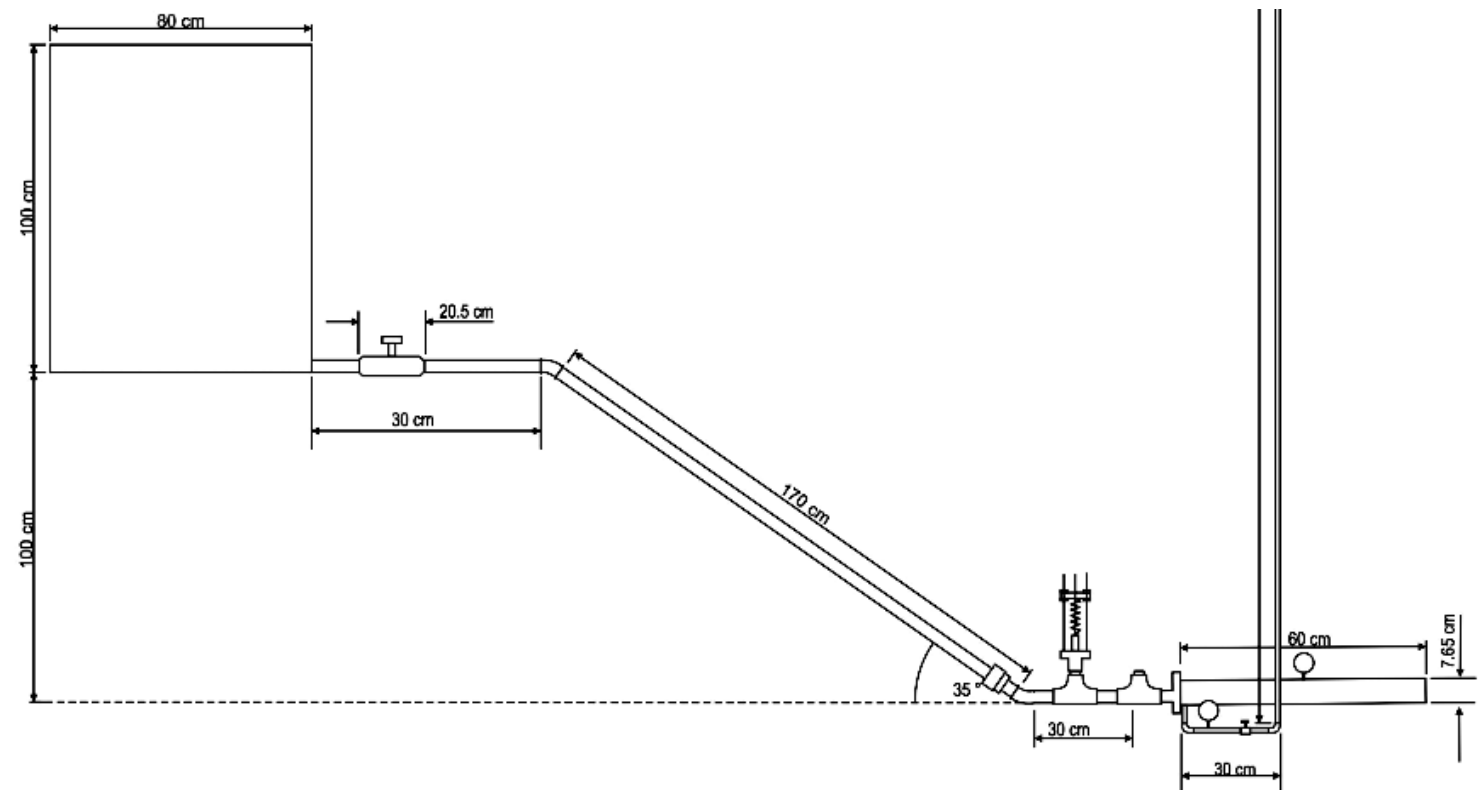

Gambar 1. Instalasi pompa hidram dengan sudut pemasangan kompresor $0^{\circ}$.

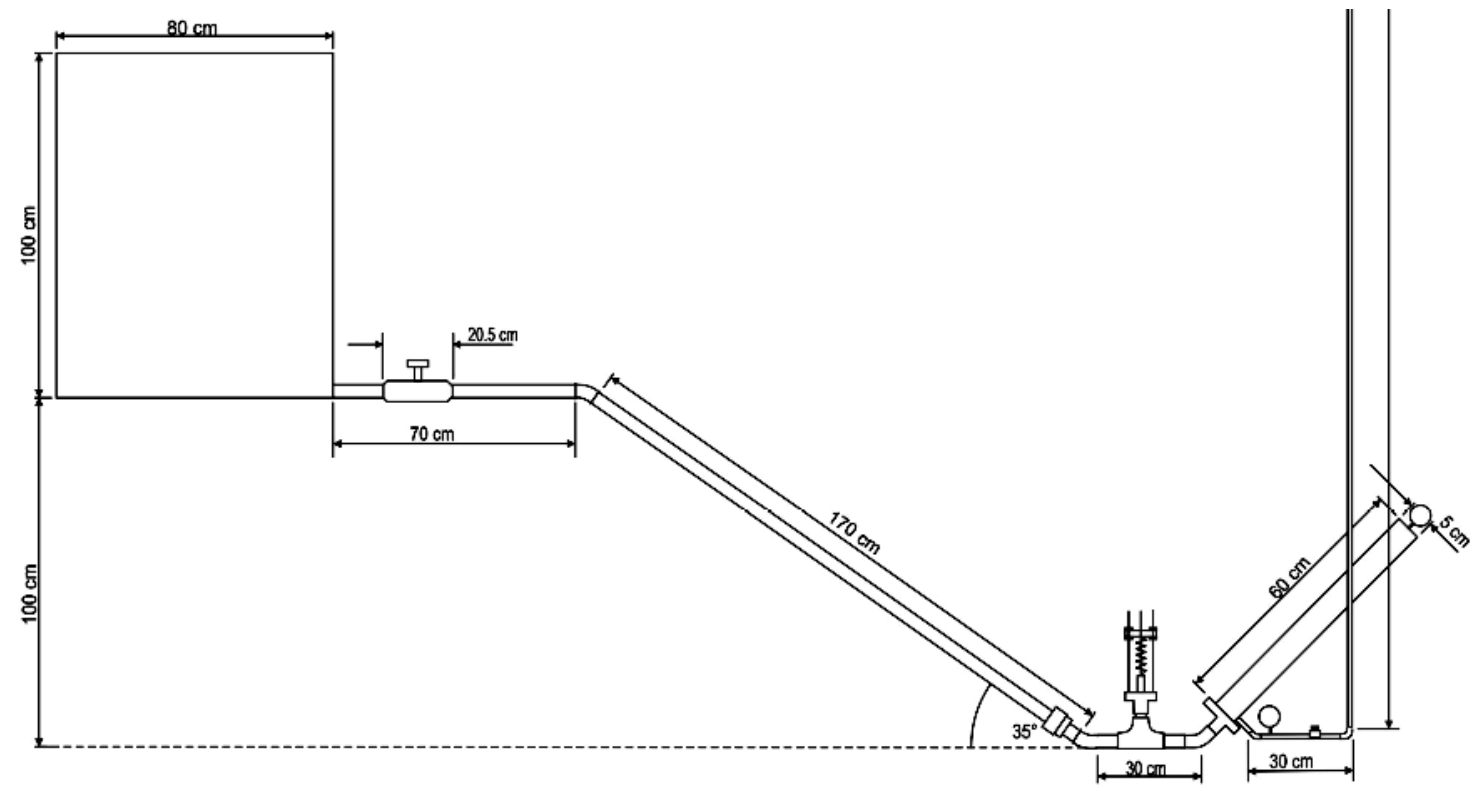

Gambar 2. Instalasi pompa hidram dengan sudut pemasangan kompresor $45^{\circ}$. 


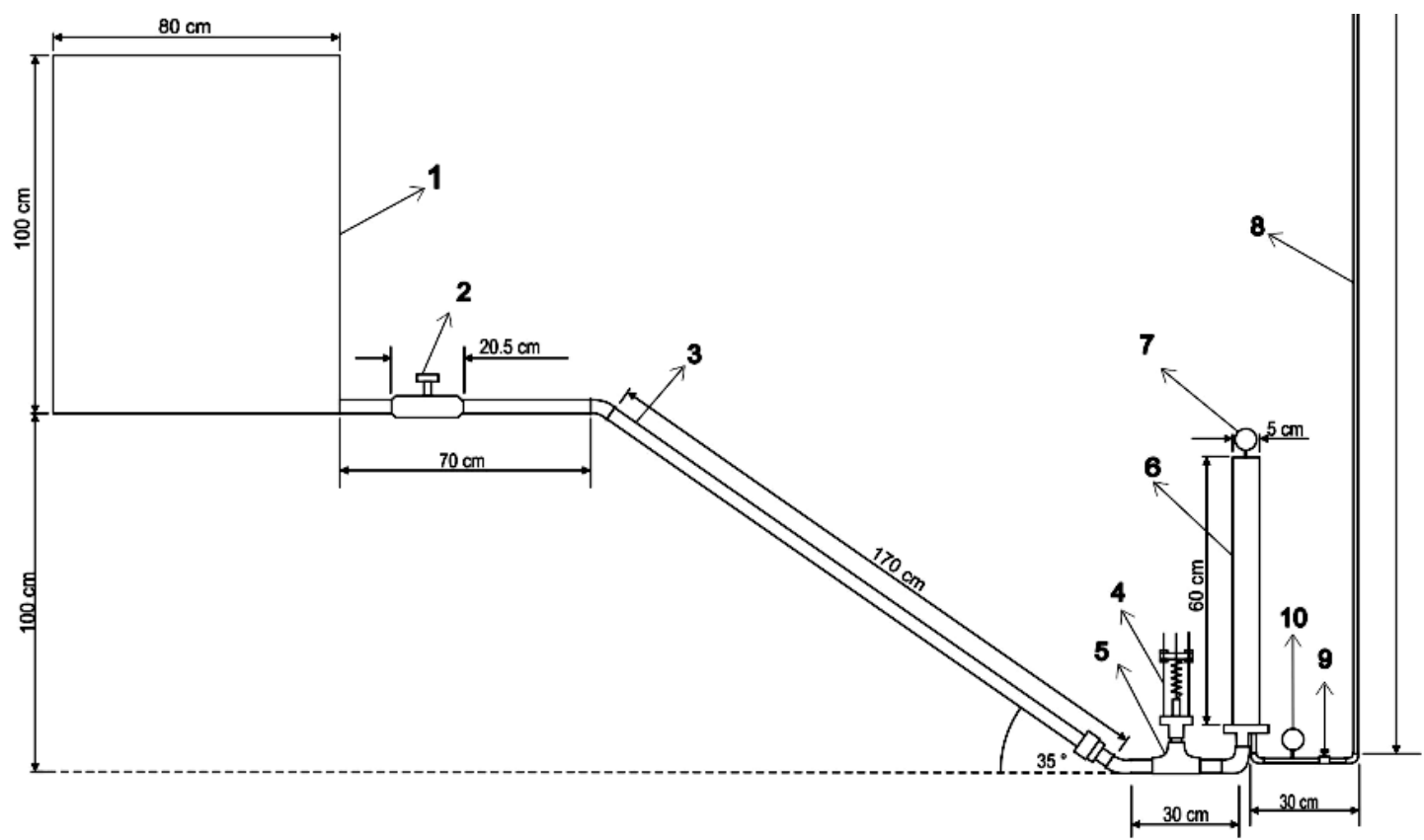

Gambar 3. Instalasi pompa hidram dengan sudut pemasangan kompresor $90^{\circ}$.

Keterangan, 1. Tangki air, 2. Kran air masuk, 3. Pipa air masuk, 4. Katup limbah, 5. Badan pompa, 6. Tabung kompresor, 7. Alat ukur tekanan pada kompresor, 8. Pipa air keluar, 9. Kran air keluar 10. Alat ukur tekanan air keluar

Adapun prosedur penelitian yang dilakukan adalah sebagai berikut,

1.Mengatur sudut terjunan yang sesuai dengan perlakuan yang diberikan yakni $35^{\circ}$.

2.Mengatur besar sudut tabung kompresor yakni $0^{\circ}$.

3.Menghubungkan sumber air dengan pipa yang telah tersedia.

4.Mengaliri air dari sumber air ke pompa hidram yang telah terpasang.

5.mengukur tekanan output, tekanan maksimum, tekanan tabung kompresi, debit air limbah, dan debit air output.

6.Mengulangi pengujian tersebut pada masingmasing variasi sudut tabung kompresor yakni $45^{\circ}$ dan $90^{\circ}$.

\section{HASIL DAN PEMBAHASAN}

Pada penelitian ini tinggi input atau terjunan $\left(h_{1}\right)$ dari dudukan pompa adalah 2 meter sedangkan tinggi keluarannya $\left(h_{2}\right)$ bervariasi dari 4 meter, 4,5 meter hingga 5 meter. Adapun untuk sudut terjunan yang digunakan $35^{\circ}$. Diameter pipa input dan outputnya masing-masing berdiameter 1,5 inci dan 0,5 inci sedangkan untuk tabung kompresor digunakan pipa galvanis dengan ukuran 3 inchi dengan tinggi $60 \mathrm{~cm}$. Pada penelitian ini juga digunakan beberapa variasi pemasangan tabung kompresor yaitu dengan pemasangan tabung $90^{\circ}, 45^{\circ}$, dan $0^{\circ}$ untuk semua variasi tinggi keluaran dari tabung itu sendiri. Proses pengambilan data debit output dilakukan dengan tiga kali pengulangan, dari tiga kali pengulangan tersebut diambil rata - rata untuk hasil yang akan digunakan dalam perhitungan.

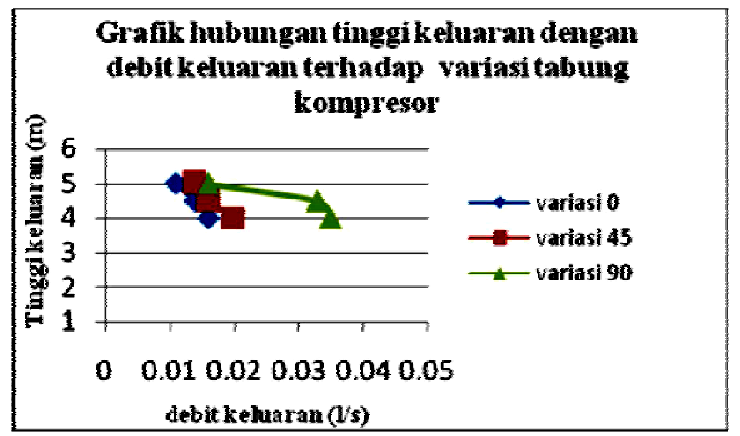

Gambar 4. Hubungan debit output dengan tinggi keluaran terhadap variasi tabung kompresor

Proses pengambilan data debit output dilakukan dengan tiga kali pengulangan, dari tiga kali pengulangan tersebut diambil rata-rata untuk hasil yang akan digunakan dalam perhitungan. 
Berdasarkan penelitian yang sudah dilakukan maka diperoleh beberapa data seperti debit input (Q1), Tekanan (P), debit output (Q2) dan efisiensi (n). Unjuk kerja pompa yang akan dianalisa pada penelitian ini adalah, debit air output (Q2), tinggi maksimum (hmaks) dan (n) efisiensi untuk semua variasi pemasangan tabung kompresor serta variasi tinggi keluaran $(\mathrm{H} 2)$.

Pada gambar 4 menunjukkan bahwa dari masing - masing variasi pemasangan tabung kompresor, debit keluaran tertinggi yaitu pada pemasangan tabung kompresor $90^{\circ}$ ini berlaku untuk setiap variasi tinggi keluaran, baik dari tinggi keluaran 4 meter 4,5 meter dan 5 meter, dan debit terkecil terjadi pada pemasangan tabung kompresor $0^{\circ}$ untuk setiap variasi tinggi keluaran. Besarnya debit keluaran ini kemungkinan level air yang terisi di dalam tabung kompresor lebih kecil untuk pemasangan $90^{\circ}$ jika dibandingkan dengan pemasangan tabung kompresor yang lainnya, kecilnya volume air di dalam tabung kompresor menyebabkan volume udara besar. Hal ini menyebabkan pompa hidram mampu mengangkat air pada head yang tinggi. Besar atau kecilnya debit keluaran dipengaruhi juga oleh ketinggian air yang diangkat.

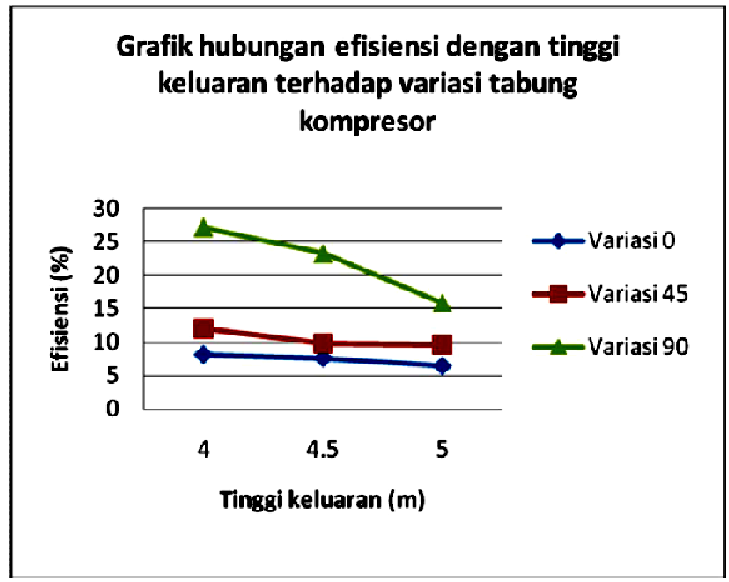

Gambar 5. Hubungan efisiensi dengan tinggi keluaran terhadap variasi tabung kompresor.

Pada gambar 5 menunjukkan bahwa efisiensi yang paling besar yaitu 27,3 \% dihasilkan pada pemasangan tabung kompresor $90^{\circ}$ untuk ketinggian 4 meter, sedangkan efisiensi yang paling kecil yaitu 6,5\% diperoleh dari ketinggian keluaran 5 meter pada pemasangan tabung kompresor $0^{\circ}$. Namun di sini terlihat bahwa efisiensi tertinggi dan terendah jika dilihat dari variasi sudut pemasangan tabung kompresor ditunjukkan pada pemasangan $90^{\circ}$ dan $0^{\circ}$, hal ini berlaku untuk setiap variasi tinggi keluaran. Besarnya efisiensi yang dihasilkan pada pemasangan $90^{\circ}$, disebabkan karena tekanan yang cenderung besar menyebabkan debit output yang dihasilkan besar. Sedangkan efisiensi terkecil dihasilkan oleh sudut pemasangan tabung kompresor $0^{\circ}$. Karena tekanan yang cenderung semakin kecil menyebabkan debit output yang dihasilkan semakin kecil. Jika dilihat dari variasi tinggi keluaran, maka efisiensi terkecil terdapat pada ketinggian 5 meter dari setiap variasi pemasangan tabung kompresor. Karena semakin panjang pipa keluaran yang digunakan maka head losses dan kerugian gesekan (friction) semakin besar. Tinggi keluaran berbanding terbalik terhadap debit output, artinya semakin tinggi head yang harus dicapai pompa, maka debit output yang dihasilkan semakin kecil begitupun juga sebaliknya.

Semakin besar debit output yang dihasilkan maka efisiensi pompa hidram akan meningkat, begitupun sebaliknya. Pada saat pengambilan data, ketiga variabel dari persamaan diatas yaitu debit output (Q2), debit input (Q1), dan tinggi keluaran ( $\left.\mathrm{H}_{2}\right)$ akan saling berhubungan satu sama yang lainnya, ketika head keluarannya ditingkatkan maka debit output menurun dan debit input meningkat menyebabkan efisiensi pompa menurun.

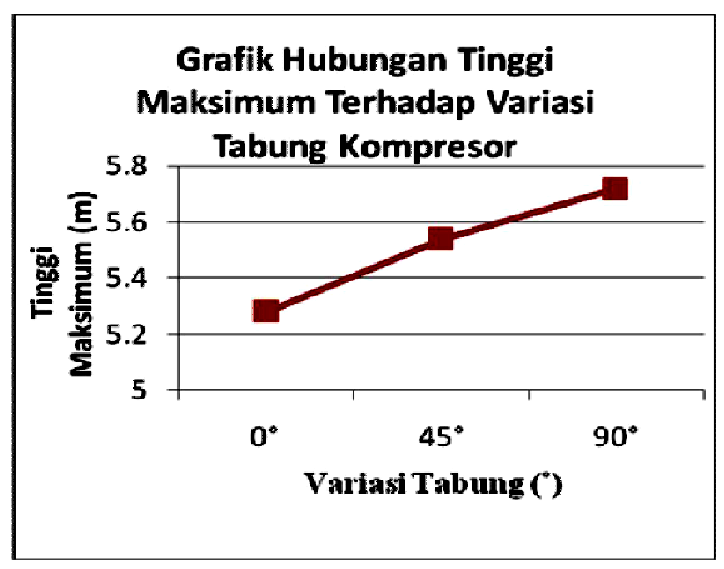

Gambar 6. Hubungan tinggi maksimum dengan variasi tabung kompresor

Hubungan antara tinggi maksimum dengan variasi tabung kompresor dapat dilihat pada gambar 6, dari ketiga variasi pemasangan tabung kompresor pada pompa hidram dicapai tinggi maksimum pada variasi pemasangan tabung kompresor yaitu $90^{\circ}$ sebesar 5,72 meter, hal ini diakibatkan karena tekanan pada tabung kompresor pada pemasangan $90^{\circ}$ lebih besar jika dibandingkan dengan pemasangan tabung $45^{\circ}$ maupun $0^{\circ}$. Besarnya tekanan pada tabung kompresor membuat tekanan yang diteruskan ke pipa keluaran akan meningkat. Sedangkan head 
maksimum yang terkecil yaitu pada pemasangan tabung kompresor $0^{\circ}$ dengan nilai 5,28 meter, hal ini menandakan tekanan pada tabung kompresor yang diteruskan ke pipa keluaran sangat kecil jika dibandingkan dengan variasi pemasangan yang lainnya. Sehingga bisa kita tarik kesimpulan bahwa pemasangan tabung kompresor $0^{\circ}, 45^{\circ}$ dan $90^{\circ}$ berbanding lurus terhadap tinggi maksimum.

\section{KESIMPULAN}

Berdasarkan data hasil perhitungan dan analisa, maka dapat ditarik kesimpulan diantaranya:

1. Dari hubungan debit keluaran dengan tinggi keluaran terhadap variasi tabung kompresor di peroleh debit output yang paling rendah pada variasi sudut $0^{\circ}$, sedangkan debit output yang paling besar dihasilkan pada variasi sudut $90^{\circ}$ ini berlaku untuk setiap variasi tinggi keluaran untuk masing-masing variasi pemasangan tabung kompresor. Dengan demikian dapat dikatakan bahwa sudut pemasangan tabung kompresor berbanding terbalik dengan debit output.

2. Semakin tinggi air angkat maka semakin kecil efisiensi yang dihasilkan. Hal ini berlaku untuk semua variasi sudut pemasangan tabung yang digunakan.

3. Pemasangan yang sudut $90^{\circ}$ mempunyai nilai head maksimum yang tertinggi yaitu 5,72 meter dan nilai terendah yaitu 5,28 meter nilai tersebut berlaku pada pemasangan variasi tabung kompresor $0^{\circ}$. Hal ini menyatakan bahwa hubungan tinggi maksimum terhadap variasi tabung kompresor berbanding lurus.

\section{DAFTAR PUSTAKA}

Ahmadi S., Mulyanto A., Sutanto R., 2014, Analisa variasi tinggi keluaran tabung kompresor terhadap unjuk kerja pompa hidram, Jurnal Dinamika Teknik Mesin, Vol 4, No 1, 7 - 16.

Jaelani A., 2011, Pengaruh pemakaian variasi tinggi serta posisi pemasangan tabung kompresor terhadap unjuk kerja pompa hidram (hydraulic ram), Skripsi, Universitas Mataram.

Juliadi H., 2011, Analisa variasi jumlah katup limbah dan susunan pompa terhadap unjuk kerja pompa hidram (hydraulic ram), Skripsi, Universitas Mataram.

Putra T., 2010, Pengujian pompa hidram sebagai pompa ramah lingkungan, Skripsi, Universitas Mataram.

Susana I.G.B., Sutanto R., 2016, Peningkatan kinerja pompa hidram berdasarkan posisi tabung kompresor dengan saluran keluar di bawah tabung kompresor, Jurnal Dinamika Teknik Mesin, Vol 6, No 2, 113 118. 